\title{
The Effect of Superheated Steam Treatment on the Quality of Vegetable Oils
}

\author{
Tomone Amatsubo, Yoshio Hagura and Kanichi Suzuki* \\ Graduate School of Biosphere Science, Hiroshima University, 1-4-4 Kagamiyama, Higashihiroshima, 739-8528, Japan
}

Received October 20, 2005; Accepted March 12, 2006

\begin{abstract}
The changes in the quality of three vegetable oils: soybean oil, corn oil and cotton seed oil, occurring during heating in superheated steam (SHS) were compared with the changes occurring during heating in hot air (HA). The temperature of both the SHS and the $\mathrm{HA}$ was $180^{\circ} \mathrm{C}$, and the heating time ranged from 30 to 180 minutes. The quality of the oils was investigated by evaluating the acid value, peroxide value, viscosity, color and odor. The acid value, the peroxide value and the viscosity of the oils heated in SHS were lower than those of the oils heated in HA. SHS-treated oils retained their fresh oil color and odor, whereas HA-treated oils changed their color and odor remarkably. Therefore, the influence of the SHS treatment on the oil quality was not significant.
\end{abstract}

Keywords: superheated steam, oxidation, viscosity, color, vegetable oil

\section{Introduction}

Edible oil and fat (oils) are very important nutritive ingredients of food, which make food taste good. Almost all foods contain oils. Large amounts of oils are also used for frying food and making cakes and breads. In recent years, consumers have paid increasing attention to the quality of the food they eat. The quality of food is considerably affected by the quality of the oils they contain. Oils are easily deteriorated by heat and/or oxygen, especially when they are composed of unsaturated fatty acids. Deteriorated oils give food a peculiar smell or taste, and they have an adverse effect our health. This is one of the main problems with processed foods because most of the food processes involve one or more thermal treatments in air at high temperatures. Under these thermal conditions, unavoidable denaturation of the oils occurs which deteriorates the quality of the food. Therefore, the development of methods to prevent the deterioration of food caused by the denaturation of oils during thermal processing is an important aim of the food industry. Usually, the deterioration level of oil is evaluated by evaluating their chemical properties such as the acid value (AV), peroxide value (POV) and iodine value, and their physical properties such as viscosity, color and refractive index. Many studies have reported changes in the properties of oil during cooking or frying. Chu et al. (2001) have reported differences in the quality change of oil used to fry shallots between gas heating and microwave oven heating. Shyu et al. (1998) have investigated the degradation of frying oil due to oxidation during vacuum frying and conventional deep frying of carrot slices. Naz et al. (2004) have compared the oxidative stability of olive, corn and soy-

* To whom correspondence should be addressed.

E-mail: suzukan@hiroshima-u.ac.jp bean oils when they were subjected to different treatment conditions. Inoue et al. (2002) have studied the changes in the quality of several vegetable oils under various frying conditions by measuring their dielectric properties, acid value, peroxide value, viscosity and density.

Recently, much attention has been focused to the application of superheated steam to food processing. Superheated steam (SHS) is a colorless, transparent $\mathrm{H}_{2} \mathrm{O}$ gas produced by heating saturated steam to a temperature above the boiling point of water. Although SHS behaves like a hot dry gas, it has many interesting properties. SHS condenses into water easily when it comes into contact with a material with a temperature lower than the boiling point of water (373 K at atmospheric pressure). Therefore, both wetting and drying occur simultaneously in SHS until the surface temperature of the material reaches the boiling point of water. The most distinctive property of SHS is that it contains no free oxygen. Thus, materials can be dried or heated in SHS under non-oxygen conditions. This treatment characteristic is unique compared to thermal processes in hot air and it has enabled the study of many applications of SHS to thermal food processing, such as drying, sterilization, baking and cooking. Iyota et al. (2001) and Prachayawarakorn et al. (2002) have reported on the drying characteristics of sliced raw potatoes and shrimps in SHS. Nishioka et al. (2004) have investigated the quality of the boiled and dried adductor muscle of the scallop (shiraboshi), and reported that SHS generates a product of high quality. Hamada et al. (2003) have studied the usefulness of SHS treatment in the sterilization of boiled dry sardine fry (shirasu-boshi). Most of these studies have investigated the changes in the quality of agricultural or marine products during SHS processing.

The objective of this study was to clarify the characteristics of edible vegetable oils subjected to SHS treatment. 
To investigate the effects of SHS treatment on the quality of the oils, the acid value, peroxide value, viscosity and color of the oils heated in SHS were compared with those of the same oils heated in hot air.

\section{Materials and Methods}

Experimental apparatus Figure 1 shows a schematic diagram of the experimental apparatus for the SHS treatment. The apparatus consisted of a boiler, a superheater, a test chamber, a water tank and a condenser. The saturated steam was generated in the boiler and then reheated in the superheater, where it converted to SHS at a proper temperature. The flow rate and temperature of the SHS were controlled by electric heaters installed in the boiler and the superheater, respectively. The cube-shaped test chamber, with each edge $150 \mathrm{~mm}$ in length, was made of stainless steel. For the hot air treatment, sample was heated in a drying oven (Drying oven SA31, Masuda).

Samples Three vegetable oils were investigated in this study: soybean oil, corn oil and cottonseed oil. The oils were purchased from Sigma Aldrich Japan and used in these experiments without any additives.

Experimental method The sample $(50 \pm 0.1 \mathrm{~g})$ was heated in SHS or hot air in a glass laboratory dish. The temperature of both the SHS and the hot air was $180^{\circ} \mathrm{C}$, and the heating time ranged from 30 to 180 minutes. Sample temperatures for both treatments reached approximately $170^{\circ} \mathrm{C}$ during heating for $30 \mathrm{~min}$, and approximately $180^{\circ} \mathrm{C}$ within 50 min. The AV, POV, viscosity, color and odor of the heated oils were measured after cooling to room temperature.

Analysis The AV (Japan Oil Chemists' Society, 2003) and POV (Japan Oil Chemists' Society, 1966) were measured according to the Standard Methods for the Analysis of Fats, Oils and Related Materials using extra pure reagents. The viscosity was measured by a capillary viscometer (Ostwald type, No. 3) at $30^{\circ} \mathrm{C}$. The oil color was measured by a color difference meter, NR-3000 (Nippon Densyoku Co., Ltd.), and evaluated according to the
Hunter $\mathrm{L}, \mathrm{a}, \mathrm{b}$ and $\Delta \mathrm{E}$ values. Each color value was expressed as a relative value to that of the corresponding fresh oil. The value of $\Delta \mathrm{E}$ was calculated with the following equation:

$$
\Delta \mathrm{E}=\left[(\Delta \mathrm{L})^{2}+(\Delta \mathrm{a})^{2}+(\Delta \mathrm{b})^{2}\right]^{1 / 2}
$$

where $\Delta \mathrm{E}, \Delta \mathrm{L}, \Delta \mathrm{a}$ and $\Delta \mathrm{b}$ are the color, lightness, redness and yellowness differences, respectively.

The change in the odor of the treated oils was given one of five grades by a sensory evaluation. Thirteen untrained students from our laboratory formed a panel for the sensory test. Five soybean oil samples were presented for evaluation: fresh oil, oil heated in SHS at $180^{\circ} \mathrm{C}$ for $60 \mathrm{~min}$, oil heated in SHS at $180^{\circ} \mathrm{C}$ for $180 \mathrm{~min}$, oil heated in hot air at $180^{\circ} \mathrm{C}$ for $60 \mathrm{~min}$, and oil heated in hot air at $180^{\circ} \mathrm{C}$ for $180 \mathrm{~min}$. The panelists smelled the five samples and graded them according to their odor intensity.

\section{Results and Discussions}

$P O V$ and $A V$ Figures 2 (a) $\sim(c)$ show the change in POV. The POV for the oil heated in hot air increased with heating time. Conversely for the oil heated in SHS, the POV decreased slightly after a slight increase at the initial stage of heating. The increase in POV represents the formation of peroxide due to the combination of oxygen with the unsaturated fatty acids in the oil. The result indicates that none or very few free oxygen molecules existed in the SHS. The small increase in POV at the initial stage of heating might have been caused by the initial reaction of the oxygen dissolved in the oil with the unsaturated portion of the oil. The subsequent slight decrease in POV is likely due to the decomposition or reduction of the unstable peroxide in the no oxygen, high temperature environment. The time dependence of the change in POV showed a similar tendency for all oils. It is known that the POV for the oils initially increases during heating and then decreases after it reaches a maximum value because the formation and decomposition of peroxides occurs consecutively in oils (Hatate et al., 1984). Also

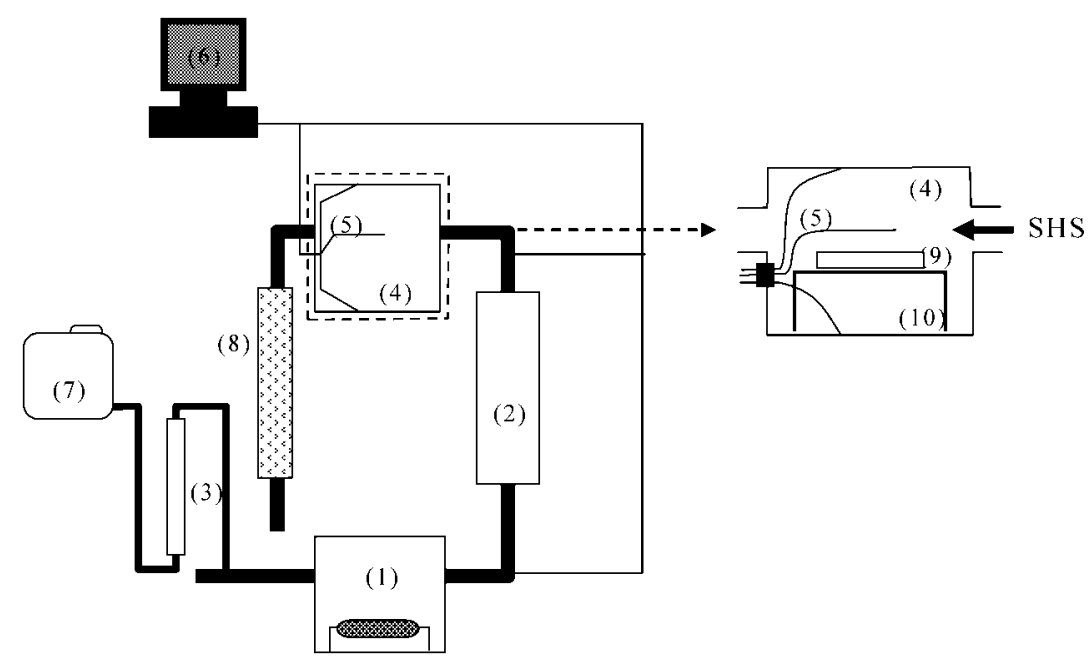

Fig. 1. Schematic diagram of the experimental apparatus. (1) Boiler, (2) Super heater, (3) Flow meter of water, (4) Test chamber, (5) Thermocouples, (6) Personal computer, (7) Water tank, (8) Condenser, (9) Glass pan, and (10) Sample stand. 
Hatate et al. (1984) have reported that the partial pressure of oxygen was closely related with the formation of peroxide.

The AVs of the three oils heated in hot air and SHS are shown in Figures 3 (a) (c). In contrast to the POV, the AV increased with heating time for both heating methods. However, the AV of the oils heated in SHS was considerably lower than that of the oils heated in hot air. The tendency of the AV to increase was exhibited similarly by all oils. The increase in AV was caused by formation of free fatty acids due to thermal decomposition of oil and peroxide (Ota and Yuki, 1977). It is believed that the degree of thermal decomposition of oil is almost the same in both hot air and SHS treatment if the sample temperature changes are similar. Therefore, the difference in AV between the oils treated in hot air and SHS was caused by the difference in the amount of peroxide formed.

The quality of oil is often determined according to the POV and AV, with lower values usually characterizing higher quality oils. Therefore, the results shown in Figures 2 and 3 indicate that the quality of the oils heated in SHS was superior to that of the oils treated in hot air. Consequently, the results suggest that the deterioration of oil in food can be largely avoided by heating the food in SHS as compared to hot air or conventional ovens.

Effect of the heating method on viscosity Oil viscosity was also affected by the treatment method and conditions, as shown in Figures 4 (a) $\sim(\mathrm{c})$. The viscosity of the oils heated in hot air increased with heating time. In contrast, the viscosity of the oils heated in SHS remained almost constant. It is widely known that when oil is heated in air, its viscosity increases with time due to the thermal
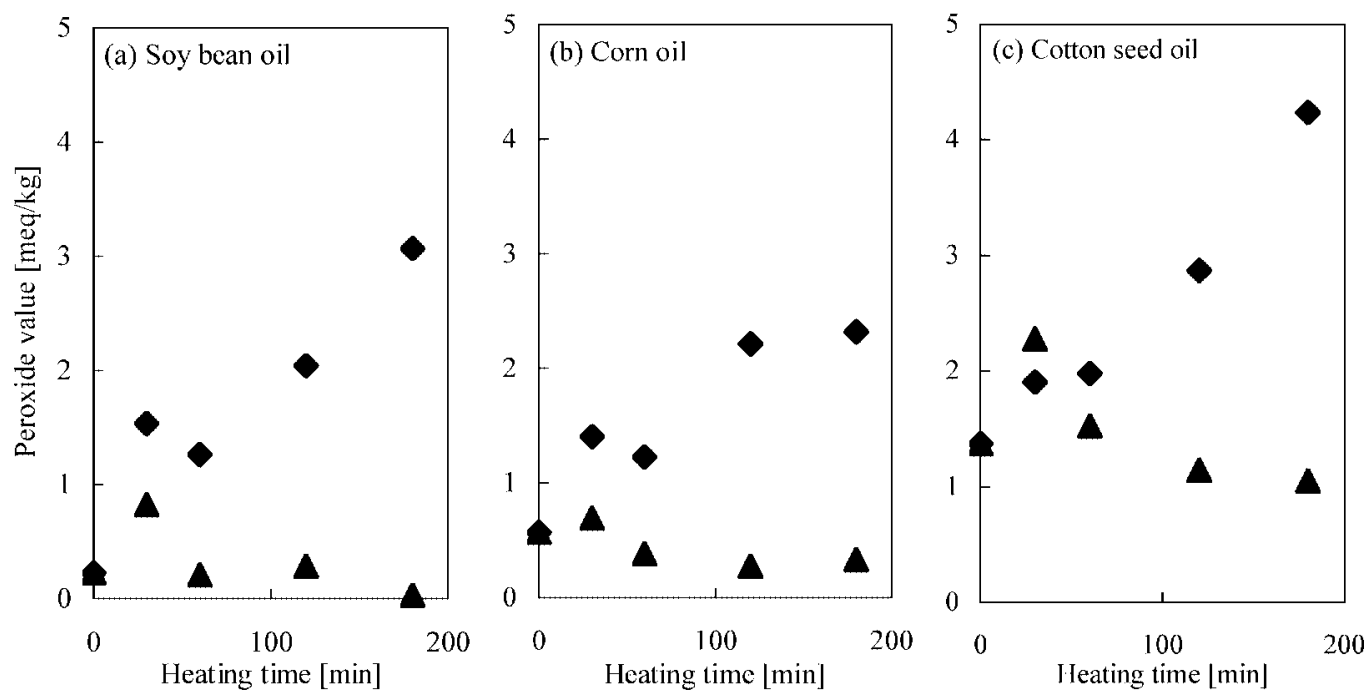

Fig. 2. Change in peroxide value of oils heated in hot air and in superheated stea.

$\diamond$; hot air

$\boldsymbol{\Delta}$; superheated steam
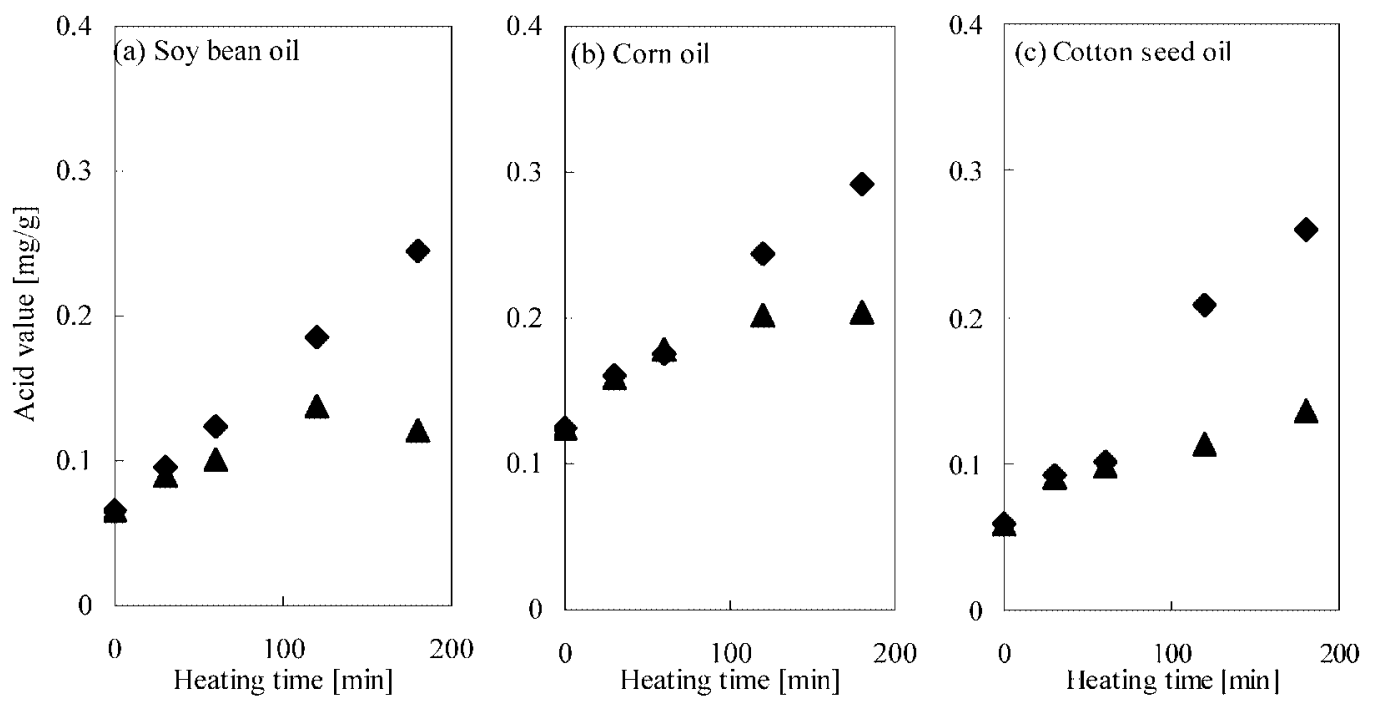

Fig. 3. Change in acid value of oils heated in hot air and in superheated steam.

$\diamond$; hot air

$\boldsymbol{\Delta}$; superheated steam 
and/or oxidative polymerization of its components (Ota, 1965; Kanemitsu and Miyagawa, 1975). In this study, the oils were heated at the same temperature $\left(180^{\circ} \mathrm{C}\right)$ in SHS and in hot air. If polymers were produced by thermal polymerization, the viscosity of the oils heated in SHS must have increased with heating time. However, as shown in Figure 4, the results of this study did not agree with this hypothesis, and indicated that the thermal polymerization rate might be very low at $180^{\circ} \mathrm{C}$. Hatate et al. (1984) have reported that higher production rates of polymers were observed at higher oxygen partial pressures and no polymers were produced during a long heating of 120 hours without oxygen. The results shown in Figure 4 suggest that the increase in the viscosity of the oils heated in hot air was primarily caused by oxidation poly- merization due to high oxygen concentration in hot air.

Comparison of color The changes in the color of soybean oil during different thermal treatments are shown in Figure 5 (a). During the first $60 \mathrm{~min}$ of heating, no significant difference in the color of the oil samples heated in hot air and SHS was detected. However, the a and b values of the oil samples heated in hot air increased gradually when the heating time exceeded $60 \mathrm{~min}$. The relative color values of the oil heated in SHS approached unity, which indicates that the fresh oil color remained unchanged during SHS treatment. The a and $b$ values are the index of redness and the index of yellowness, respectively. The higher the a value, the redder the material and the higher the $\mathrm{b}$ value, the yellower the material. Thus, Figure 5 (a) shows that hot air treatment darkened
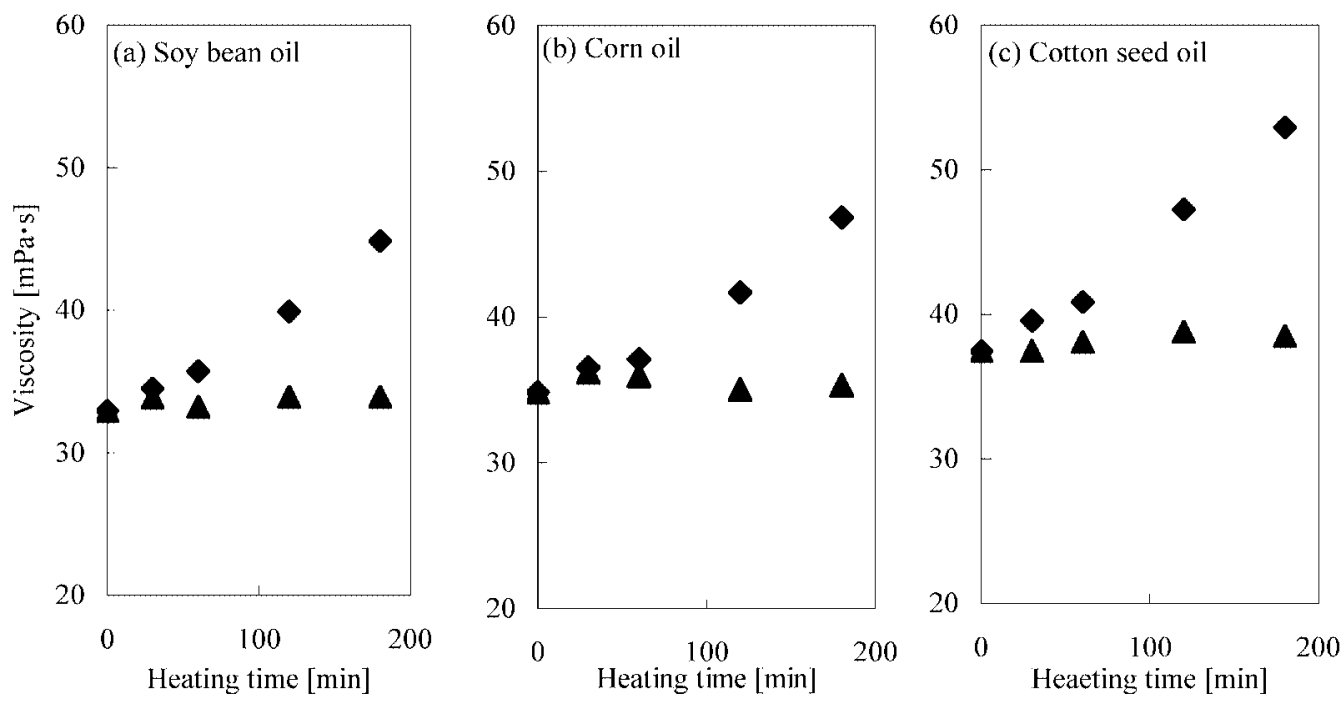

Fig. 4. Comparison of viscosity change of oils heated in hot air with that heated in superheated steam. $\bullet$; hot air $\mathbf{\Delta}$; superheated steam
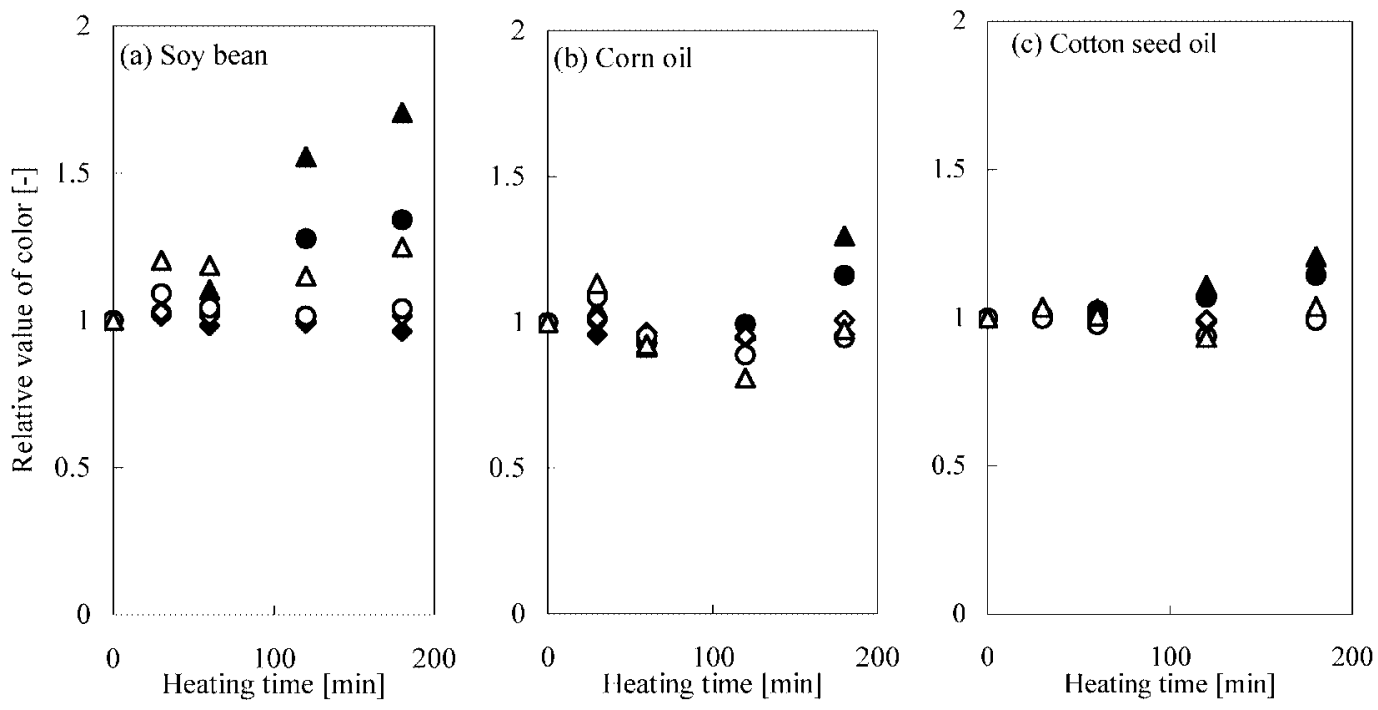

Fig. 5 Changes in color of oils heated in hot air and superheated steam.

Hot air: $\diamond$;,$~ ;$ a, $\boldsymbol{\Delta}$; b.

Superheated steam: $\diamond ; \mathrm{L}, \bigcirc$; a, $\triangle$; b. 
Table 1. Color difference $\Delta \mathrm{E}$ between the fresh oil and the oil heated in hot air or in superheated steam.

\begin{tabular}{|c|c|c|c|c|c|c|}
\hline $\begin{array}{c}\text { Heating } \\
\text { time [min] }\end{array}$ & \multicolumn{2}{|c|}{ Soy bean oil } & \multicolumn{2}{c|}{ Corn oil } & \multicolumn{2}{c|}{ Cotton seed oil } \\
\cline { 2 - 7 } & Itot air & $\begin{array}{c}\text { Superheated } \\
\text { steam }\end{array}$ & Itot air & $\begin{array}{c}\text { Superheated } \\
\text { steam }\end{array}$ & Hot air & $\begin{array}{c}\text { Superheated } \\
\text { steam }\end{array}$ \\
\hline 60 & 0.77 & 1.08 & 1.25 & 1.24 & 0.37 & 0.14 \\
\hline 180 & 4.17 & 1.40 & 2.49 & 0.33 & 1.61 & 0.26 \\
\hline
\end{tabular}

Table 2. Sensory evaluation of the odor of fresh soybean oil and oil heated under four different heating conditions.

\begin{tabular}{|c|c|c|c|c|c|}
\hline Heating condition & First & Second & Third & Fourth & Fifth \\
\hline lresh oil & 0 & 0 & 6 & 3 & 4 \\
\hline $60 \mathrm{~min}$ in $\mathrm{sHS}$ & 0 & 0 & 1 & 4 & 8 \\
\hline $180 \mathrm{~min}$ in SIIS & 1 & 0 & 5 & 6 & 1 \\
\hline $60 \mathrm{~min}$ in IIA & 0 & 12 & 1 & 0 & 0 \\
\hline $180 \mathrm{~min}$ in $\mathrm{H} \Lambda$ & 12 & 1 & 0) & 0 & 0 \\
\hline
\end{tabular}

Intensity of odor: First $>$ Second $>$ Third $>$ Fourth $>$ Fifth

SIIS: superheated steam, IIA: hot air

the color of the oils. Table 1 shows the color difference between the fresh and the heated oils. The results also indicate that the value of $\Delta \mathrm{E}$ for soybean oil heated in hot air was three times higher than that for soybean oil heated in SHS for $180 \mathrm{~min}$. The difference between the colors of the two samples could be visually recognized.

Figures 5 (b) and (c) show the changes in the color of corn and cotton seed oils, respectively. Compared with the results for soybean oil, smaller changes in color were observed for these two oils, although the tendency of the color change was similar. This might be due to the differences in natural color of the fresh oils, or to the different concentrations of heat sensitive oil components such as carotene.

Odor of heated oils Table 2 shows the results of the sensory evaluation of the odor of fresh soybean oil and oil heated under four different heating conditions. The first and fifth represent the oil samples with the strongest odor and the weakest odor among the five oil samples (fresh oil and four heated oils). Each number in the table indicates the number of panel members who recognized the proper order of odor intensity. Six of 13 panel members placed fresh soybean oil third, and 12 of 13 panel members placed soybean oil heated in hot air at $180^{\circ} \mathrm{C}$ for $180 \mathrm{~min}$ first among the five oil samples. Notably, the oil heated in SHS for 60 min was perceived as having the weakest odor intensity and there was no significant difference between the oil heated in SHS for 180 min and the fresh oil. These results suggest that there is a distinct difference between the odor of oil heated in hot air and that of oil heated in SHS. Accordingly, it was demonstrated that oil heated in SHS has no oily odor compared to oil heated in hot air.

From the above results, it is clear that superheated steam inhibits the thermal deterioration of vegetable oils.

\section{Reference}

Chu, Y.H. and Hsu, H.F. (2001). Comparative studies of different heat treatments on quality of fried shallots and their frying oils, Food Chem., 75, 37-42.

Hamada, M., Kawamura, K., Ura, H. and Fugisawa, H. (2003). Sterilization of boiled-dry sardine fry, Shirasu-boshi, by superheated steam heating, J. National Fisheries Univ., 51 (3), 67-72 (in Japanese).

Hatate, Y., Fure, H. and Ikari, A. (1984). Degradation of fats and oils by autoxidation (I) Production rate of peroxides and polymers in the autoxidation of oleic acid, The research reports of the Faculty of Eng., Kagoshima Univ., 26, 95-102. (in Japanese).

Inoue, C., Hagura, Y., Ishikawa, M. and Suzuki, K. (2002). The dielectric property of soybean oil in deep-fat frying and the effect of frequency, J. Food Sci., 67 (3), 1126-1129.

Iyota, H., Nishimura, N., Onuma, T. and Nomura, T. (2001). Drying of sliced raw potatoes in superheated steam and hot air, Drying Technology, 19 (7), 1411-1424.

Japan Oil Chemists' Society (1966), "Standard methods for the analysis of fats, oils and related materials", pp. 171-173.

Japan Oil Chemists' Society (2003), "Standard methods for the analysis of fats, oils and related materials", p. 2. 3. 1-1996.

Kanemitsu, Y. and Miyagawa, K. (1975). Flow properties of heated oils (part 1) flow properties of cottonseed, soybean and rapeseed oils, J. Home Econ. Jpn., 26 (8), 571-575 (in Japanese).

Naz, S., Sheikh, H., Siddiqi, R. and Sayeed, S. A. (2004). Oxidative stability of olive, corn and soybean oil under different conditions, Food Chem., 88, 253-259.

Nishioka, F., Asaoka, D. and Yamazaki, M. (2004). The research on the high quality of the boiled-dried adductor muscle of scallop (Shiraboshi) using the superheated steam, Nippon Shokuhin Kagaku Kogaku Kaishi, 51 (3), 167-171 (in Japanese).

Ota, S. (1965). Deterioration of frying oils, J. Jpn. Oil Chem. Soc., 14 (12), 88-94 (in Japanese).

Ota, S. and Yuki, E. (1977). Hydrolysis of edible fats and oils, Yukagaku, 26 (3), 150-164 (in Japanese).

Prachayawarakorn, S., Soponronnarit, S., Wetchacama, S. and Jaisut, D. (2002). Desorption isotherms and drying characteristics of shrimp in superheated steam and hot air, Drying Technology, 20 (3), 669-684.

Shyu, S.L., Hau, L.B. and Hwang, L.S. (1998). Effect of vacuum frying on the oxidative stability of oils, JAOCS, 75 (10), 13931398. 